
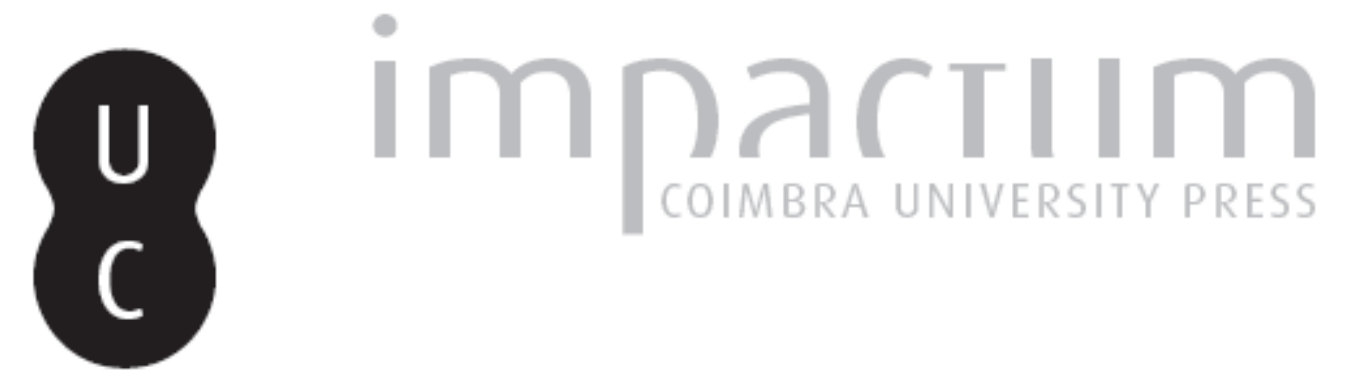

\title{
Denso: uma divindade lusitana revisitada
}

Autor(es): $\quad$ Prósper, Blanca María; Redentor, Armando

Publicado por: Faculdade de Letras da Universidade de Coimbra

URL persistente:

URI:http://hdl.handle.net/10316.2/37752

DOI:

DOI:http://dx.doi.org/10.14195/1647-8657_46_10

Accessed : $\quad$ 26-Apr-2023 13:54:14

A navegação consulta e descarregamento dos títulos inseridos nas Bibliotecas Digitais UC Digitalis, UC Pombalina e UC Impactum, pressupõem a aceitação plena e sem reservas dos Termos e Condições de Uso destas Bibliotecas Digitais, disponíveis em https://digitalis.uc.pt/pt-pt/termos.

Conforme exposto nos referidos Termos e Condições de Uso, o descarregamento de títulos de acesso restrito requer uma licença válida de autorização devendo o utilizador aceder ao(s) documento(s) a partir de um endereço de IP da instituição detentora da supramencionada licença.

Ao utilizador é apenas permitido o descarregamento para uso pessoal, pelo que o emprego do(s) título(s) descarregado(s) para outro fim, designadamente comercial, carece de autorização do respetivo autor ou editor da obra.

Na medida em que todas as obras da UC Digitalis se encontram protegidas pelo Código do Direito de Autor e Direitos Conexos e demais legislação aplicável, toda a cópia, parcial ou total, deste documento, nos casos em que é legalmente admitida, deverá conter ou fazer-se acompanhar por este aviso.

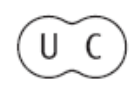




\section{CONIMBRIGA}

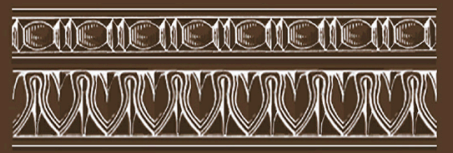

INSTITUTO DE ARQUEOLOGIA

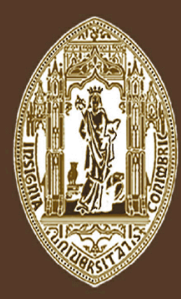

VOLUME XLVI - 2007

FACULDADE DE LETRAS UNIVERSIDADE DE COIMBRA 
Blanca María PrósPer

Universidade de Salamanca

ARMANDO REDENTOR

Bolseiro de Investigação Científica da FCT

DENSO: UMA DIVINDADE LUSITANA REVISITADA

"Conimbriga" XLVI (2007) p. 251-265

Resumo: Reavalia-se uma inscrição de Cilhades (Felgar, Torre de Moncorvo) identificada no final da década de 50 do século transacto, revalidando-se o seu carácter votivo.

Para além do enquadramento histórico-arqueológico do monumento, procede-se à sua análise epigráfica e ao estudo linguístico da invocação que documenta: DENSO. Esta interpreta-se como nume protector de um aglomerado populacional, apelidado em função de uma das suas principais qualidades: ser "dotado de força mágica". A dedicatória é efectuada por indivíduo com tria nomina e filiação em sigla.

ABSTRACT: An inscription from Cilhades (Felgar, Torre de Moncorvo) identified in the end of the 1950ies is re-evaluated, its votive character being confirmed.

An analysis of the monument in its historical and archaeological framework is undertaken, followed by the epigraphical analysis and linguistic study of the invocation it displays: DENSO. This is interpreted as being a protective god of a settlement, named after one of its main qualities: "to be endowed with magical force". The dedication is made by an individual with acronym tria nomina and filiation. 
(Página deixada propositadamente em branco) 


\section{DENSO: \\ UMA DIVINDADE LUSITANA REVISITADA}

\section{Introdução}

$\mathrm{Na}$ margem direita do rio Sabor, permanece adormecida uma povoação, com cerca de uma vintena de casas xistentas rodeando uma pequena capela que tem por orago São Lourenço. É Cilhades o seu nome e pertence à freguesia de Felgar, concelho de Torre de Moncorvo. A magia do sítio, hoje despovoado, não deixa indiferente quem teime a travessia do Sabor e excursione até lá1. Os felgarenses crêem ter sido aí o berço da freguesia, quiçá induzidos pelas evidências arqueológicas de ocupação na margem desse troço do rio.

Poucas centenas de metros a nordeste do aglomerado de casas, ergue-se, num pequeno esporão, o Castelinho ou Castelo de Cilhades, com uma linha de muralha e um torreão voltado para o colo de acesso. Os materiais observáveis à superfície não indiciam sobrevivência na época romana, parecendo a sua ocupação circunscrever-se à Idade do Ferro $^{2}$.

Entre este povoado e a povoação de Cilhades localiza-se o habitat romano conhecido como Quinta de Cilhades, sendo crível que represente, relativamente ao Castelinho, a solução de continuidade da ocupação deste sector do vale do Sabor, onde, além de antropossolos de xisto, também ocorrem aluviões riquíssimos carreados pelo seu curso. Os solos encontram-se pejados de fragmentos de cerâmicas romanas: de uso comum, finas de importação e de construção ${ }^{3}$. No laranjal da Quinta

1 O melhor acesso é a partir do Felgar, que se localiza a nascente do rio.

2 O local foi objecto de escavação clandestina que destruiu parcialmente a muralha num sector contíguo ao torreão e pôs a descoberto um muro de uma construção no interior da área amuralhada. À superfície observam-se fragmentos de cerâmica manual atribuível à Idade do Ferro. Cf. F. S. Lemos (1993, p. 353-354, n. ${ }^{\circ}$ 680) e C. CRUZ (2000, p. 186-187, n. $\left.{ }^{\circ} 164\right)$.

3 Vide F. S. Lemos (1993, p. 354-355, n. ${ }^{\circ}$ 681) e C. CRUZ (2000, p. 268-269, n. $\left.{ }^{\circ} 320\right)$. 
de Cilhades, pertencente à família da Sra. D. Ester Carneiro Neves Filipe, falecida ${ }^{4}$, apareceu, em 1959, uma inscrição votiva de granito, havendo ainda a registar no local diversos elementos arquitectónicos, nomeadamente bases e fustes de colunas, além de outros elementos de cantaria.

Comunicada a existência da epígrafe por J. Santos Júnior a D. Domingos de Pinho Brandão, deslocou-se este ao local, na companhia de Adriano Vasco Rodrigues, em Setembro de 1960, tendo realizado no ano seguinte a sua publicação ${ }^{5}$, dando destaque ao facto de a pedra preservar o nome de uma divindade indígena até então desconhecida.

Apesar de confessar que chegou a equacionar a hipótese de estar perante uma inscrição honorífica dedicada a um indivíduo de nome Denso, D. Domingos de Pinho Brandão acaba por afirmar o seu carácter votivo e estabelecer a seguinte leitura: DENSO / $\overline{\mathrm{VA}} \mathrm{R}(u) \mathrm{S} \mathrm{C}($ aii $)$ F(ilius) / LIBENS DICAVIT.

No respeitante à tipologia do monumento, regista indecisão entre a sua classificação como ara ou como plinto de uma estátua (em honra da divindade), incutida pelo facto de se encontrar fragmentado no topo, embora a primeira hipótese lhe pareça mais adequada 6 .

A inscrição foi objecto de referências posteriores, mas até ao presente não havia sido realizada qualquer reavaliação do monumento, apesar da forma dubitativa como em alguma da bibliografia ulterior é feita alusão à interpretação do seu texto.

Em missiva enviada a J. d'Encarnação, datada de 1969, Pinho Brandão reafirma a importância da inscrição pela referência a uma nova divindade, mas não considera irrefutável a leitura proposta para a 1. 2; todavia, aquele investigador aceita a lição divulgada pelo prelado portuense, achegando que residiria no adjectivo libens a razão que o teria impelido a atribuir carácter votivo ao texto, apesar de libens dicauit não ser fórmula trivial, sobretudo, quando comparada com libens soluit ${ }^{7}$.

4 Agradecemos a sua filha, Dra. Maria Beatriz Neves Filipe, as facilidades concedidas para o estudo da epígrafe. Estendemos, ainda, o nosso agradecimento ao Dr. Nelson Rebanda, que nos orientou na busca do seu paradeiro.

5 D. de P. BRANDÃo (1961, p. 26-28).

6 Ressalta a reduzida dimensão para plinto, apesar de o formulário final poder sugerir esta hipótese.

7 J. D’ENCARNAÇÃO (1975, p. 173-174). 
Posteriormente, Alain Tranoy concorda com o carácter votivo da epígrafe, ressaltando a dificuldade interpretativa que envolvem textos como este, em que o teónimo constituiria o único elemento utilizável ${ }^{8}$.

José Manuel Garcia, classificando a epígrafe como cipo, não dá total credibilidade às interpretações anteriores e coloca o teónimo sob interrogação 9 . À incerteza do teónimo, porque, em seu entender, a palavra poderá relacionar-se com o adjectivo latino densus, também com utilização cognominal, junta o inusitado da fórmula final, alegando, porém, o carácter votivo do monumento em função da presença de libens, argumento anteriormente explanado por J. d'Encarnação. As suas reservas estendem-se ainda - e com razão, tal como havia alertado D. Domingos de Pinho Brandão ${ }^{10}$ - à interpretação da 1. 2.

A última publicação que refere a inscrição faz-se eco do trabalho de D. Domingos de Pinho Brandão, posição compreensível se atentarmos no facto de um dos autores ser Adriano Vasco Rodrigues ${ }^{11}$.

\section{Estudo epigráfico da inscrição de Cilhades}

Do ponto de vista tipológico, a epígrafe é classificável como ara, apesar do estado de conservação do seu remate. As suas dimensões ${ }^{12}$ máximas são [82] x 33 x 34 .

Fracturada superiormente, quase nada resta do capitel ([6] x [30] x [30]), permanecendo perceptíveis, todavia, ténues vestígios da moldura de ligação ao fuste ( 37 x 29 x 30). Este apresenta a aresta anterior direita danificada a toda a altura, com sequelas ao nível do final das linhas do texto, ao passo que a esquerda se mostra parcialmente abrasada devido à sua utilização como afiador, circunstância que afecta o início da 1. 2 . A base (39 x 33 × 34), contrariamente ao fuste, que se apresenta com acabamento em todas as faces, apenas na anterior aparece integralmente alisada; a posterior foi poupada a esse aperfeiçoamento final, tal como

8 A. TRANOY (1981, p. 298).

9 J. M. GARCIA (1991, p. 307-308, n. ${ }^{\circ}$ 59).

10 Vide supra.

11 M. da C. Carqueja \& A. V. Rodrigues (2006, p. 43-44). Como vimos, Adriano Vasco Rodrigues acompanhou D. Domingos de Pinho Brandão aquando da visita ao local de achado do monumento.

12 As medidas indicam-se em centímetros. 
parte das faces laterais, onde apenas sofreu acabamento uma faixa de 6 a $8 \mathrm{~cm}$ de altura, indiciando que a peça se destinaria a estar encaixada ou semienterrada.

O texto ocupa a face anterior do fuste a toda a altura, surgindo associado a linhas auxiliares bem vincadas que ressaltam como efeito estético. Duas das quatro linhas de texto referenciam a divindade à qual é consagrado o monumento e o dedicante, ao passo que as seguintes se reservaram para a fórmula votiva.

A leitura veiculada originalmente, tanto quanto era possível avaliar a partir das fotos e desenho publicados, sempre nos mereceu crédito, à excepção da 1. 2, tal como alertavam os comentários dubitativos que foram sendo registados a esse propósito. A pertinência das dúvidas levantadas a propósito desta linha levou-nos a realizar a autópsia do monumento.

Tal como arriscou D. Domingos de Pinho Brandão, não cremos haver razão para que a primeira letra da 1.1 não seja um $\mathrm{D}$, sobretudo quando cotejada com a primeira da 1. 4, para a qual não se deve admitir a existência do nexo DE, tal como igualmente ele, com bom critério, discerniu. Vemos, porém, artificiosa a proposta de leitura da 1. 2, para a qual este mesmo investigador admitiu a existência do nexo VA (putativamente dubitável pela ausência de travessão) e a omissão do V necessário à desinência nominativa do nome do dedicante. A análise que realizámos à inscrição autoriza-nos a considerar a existência de um M no início da linha, pelo que preferimos interpretar abreviado, por meio de siglas, o nome do dedicante.

\section{DENSO / M(arcus) R(---) S(---) C(aii) F(ilius) / LIBENȘ / DICAVIT}

A Denso. Marco $\mathrm{R}(\ldots) \mathrm{S}(\ldots)$, filho de Caio, dedicou de boa vontade.

Alt. das letras: 1.1 e $2: 6 / 6,3 ; 1.3: 5,8 / 6,3 ; 1.4: 5,5 / 6,3$. Espaços: 1 : $2 ; 2: 2,5 / 2,9 ; 3$ e $4: 2,5 ; 5: 2,2 / 2,5$.

A paginação parece ter sido executada em função de duplo alinhamento à esquerda, uma vez que as 1. 3-4 registam ligeiro avanço em relação às 1. 1-2.

A gravação das letras, definíveis como capitais alongadas, é em bisel, fino e pouco profundo. Todavia, o seu ductus revela-se não muito regular, tendo algumas moderada inclinação para a frente (1. 1: S; 1. 2: 
F; 1. 3: L; 1. 4: D). A extremidade superior dos SS (1. 1 e 2), a pança superior do B e a barra superior do E (1. 3) apresentam-se serifadas; o F (1. 2) não dispõe de barra inferior e o A (1. 4) não apresenta travessão. O espaçamento entre as linhas auxiliares é de $9 \mathrm{~cm}$ e os caracteres gravaram-se a $1 \mathrm{~cm}$ dessas guias, com excepção do $\mathrm{M}$ e do $\mathrm{R}$ (1. 2), que descem até à linha.

Hipótese levantada desde a primeira hora, e que, apesar de prontamente afastada nessa altura, não parece ter sido totalmente desacreditada, é a que equaciona o facto de a inscrição poder ter tido carácter honorífico, acalentando-se no facto de o adjectivo latino densus ter utilização antroponímica ${ }^{13}$. De facto, assim é, mas se observarmos a frequência da sua utilização enquanto antropónimo verificamos que é baixíssima. Apenas se atesta na Hispânia, onde se conhece um testemunho soriano ${ }^{14}$.

Esta hipótese, que a nosso ver a fórmula final indiscutivelmente contraria, não nos pareceria, de todo o modo, a mais viável, pois se a aceitássemos teríamos de avaliar a circunstância de o homenageado estar apenas identificado por um nome único. Que sentido teria a homenagem e que importância revestiria ela na comunidade em que teria sido levada a cabo? Seria razoável aceitar a existência de um laço de parentesco próximo com o dedicante, que, ao invés do homenageado, afirma a sua ingenuidade? Damos, assim, crédito à interpretação do monumento como dedicatória votiva, discutindo-se mais abaixo os contornos linguísticos da voz que assumimos como teónimo.

Discordamos, porém, da interpretação do nome dedicante que assentou D. Domingos de Pinho Brandão, como acima explanámos, pois não cremos aceitável o nexo VA, que, na sua lógica interpretativa, acaba por induzir a necessidade de considerar a omissão de um V para formar o nome Varus.

Comparativamente a Densus, Varus encontra-se mais bem representado, quer à escala imperial, quer na península hispânica ${ }^{15}$, mas cre-

13 Vide I. KaJAnto (1965, p. 71 e 289).

14 Trata-se de uma inscrição de Vinuesa (CIL II 2886), na qual a sua função cognominal é clara; alguma bibliografia inclui, ainda, como testemunho deste cognome uma outra inscrição soriana, referente a San Esteban de Gormaz (CIL II 2815), todavia, neste caso, estaremos, verosimilmente, perante um gentilício: Densius. Cf. B. LöRINCZ (1999, p. 97) e J. M. Abascal PALAZón (1994, p. 281).

15 Tem na Hispânia representação idêntica à que tem na Narbonense, sendo apenas suplantada pelos testemunhos itálicos, constituindo estas as três áreas geo- 
mos que, à luz da autópsia realizada, será mais correcta a admissão da redução da identificação do dedicante a siglas ${ }^{16}$. Esta interpretação pode ainda ver-se apoiada pelo facto de a indicação da filiação com recurso a um praenomen, embora em posição não canónica ${ }^{17}$, ser mais acorde com uma estrutura onomástica trinominal, a não ser que considerássemos estar perante um caso de simplificação onomástica. Não obstante esta prática ter confirmação em espaço territorial adjacente ${ }^{18}$, ela surge numa fase cronológica posterior à que julgamos dever atribuir a ara de Cilhades.

Os elementos disponíveis para datação desta inscrição não são abundantes. A paleografia, embora se reconheça a falibilidade que tem subjacente, orienta-nos para uma cronologia do século II ou início do século III (Severos), que, de algum modo, acaba por quadrar com a utilização de tria nomina por parte do dedicante. A fórmula final não nos acrescenta qualquer elemento para mais apurada decisão, pelo que consideramos ajustada a atribuição ao monumento de uma cronologia lata, balizada entre 100 e 250 .

As possibilidades que poderíamos apontar para desdobrar um cognome com a inicial S são imensas, pelo que não nos aventuramos a fazer qualquer proposta. Quanto aos gentilícios iniciados por R, as opções são mais reduzidas se contarmos apenas com os que têm comprovação em solo hispânico, mas ainda assim suficientes para não $\operatorname{arriscar}^{19}$.

gráficas com maior número de testemunhos (10, 9 e 14, respectivamente): B. LöRINCZ (2002, p. 148).

16 Esta prática encontra-se atestada em multíplices testemunhos votivos peninsulares.

17 São conhecidos exemplos epigráficos em que a filiação surge após tria ou duo nomina, com patronímico não abreviado e, inclusive, com praenomina por extenso, bem compreensíveis em ambientes recém aculturados, mas também não carece de paralelos a filiação em sigla após estruturas onomásticas daqueles tipos. No caso vertente, quiçá represente estratégia comunicativa, pois a colocação das duas letras da filiação entre as iniciais do nomen e do cognomen tenderia a perturbar a interpretação siglada do nome do dedicante, sobretudo quando sabemos que, pelo menos em contextos de menor aculturação, é frequente a utilização das estruturas onomásticas latinas dissociadas da filiação.

18 Cf. M. Navarro Caballero (1998, p. 189).

19 No Nordeste transmontano não conhecemos qualquer testemunho de gentilício começado por R, mas no Norte da Lusitânia, província a que provavelmente devemos atribuir a inscrição, localizando-se os Banienses a norte do Douro, documenta-se Rufinius (GRUPO MÉRIDA, 2003, p. 282-283, mapa 257). 


\section{Estudo linguístico do teónimo}

As possibilidades de interpretação etimológica de uma divindade DENSO são, evidentemente, limitadas. Como já oportunamente se expôs $^{20}$, as divindades de toda a área lusitano-galaica conhecem dois tipos de manifestações muito estereotipadas. Com maior frequência, está-se perante apelativos da língua comum, habitualmente respeitantes a ocorrências naturais, os quais são entendidos como divindades ou como abrigo ou manifestação física destas, tratando-se, em todo o caso, de substantivos, como COSSVE "confluência" ou BANDVE "passagem". Alternativamente, pode tratar-se de epítetos sufixados, isto é, adjectivos que se referem ao nome próprio ou à pertença local da divindade, ao lugar do qual é protectora ou onde habita, sem que a mesma seja directamente nomeada. Daqui se deduz que a manifestação mais complexa é aquela em que surge a sequência «teónimo + epíteto», que não é mais do que o lugar onde o nume existe ou com o qual ele se identifica, seguido da determinação da realidade local que protege, como em BANDVE AETOBRIGO "à divindade (que guarda a) passagem de Aetobris", REVE REVMIRAECO "ao rio Reumira" ante MIRAECO "ao (rio ou divindade fluvial) MIRAECO" ou, em fórmulas mistas, BANDI OGE(LAECO) perante o latinizado LARI OCAELAECO.

Como revela o caso de DENSO, não se esgota por aqui, porém, a totalidade das possibilidades. De facto, existe um terceiro tipo, comparativamente minoritário, que é meramente constituído por um adjectivo que qualifica a divindade, ressaltando alguma das suas principais qualidades, de entre as que o tornam mais atractivo como protector da comunidade. Dois exemplos que podem servir para ilustrar esta situação são EDIGENIO (Mérida) e AETIO (Castelo Branco). Longe de poderem ser considerados como epítetos locais, temos, no primeiro caso, um deus do renovamento. Se partirmos do substantivo *eti-gena/a "estirpe", estaremos perante uma divindade do renascimento, que assegura a continuidade da descendência ou a fertilidade do campo. Neste caso, a sufixação em *-(i)yo- estabelece a relação entre a divindade entendida como ser personificado e a coisa com a qual tem relação ou na qual habita. No segundo caso, o que temos é um adjectivo que provém provavelmente de *aiti-(i)yo-, por sua vez procedente do nome de

20 B. M. PRÓSPER (2002). 
acção *ai-ti- da raiz *ai- "dar", que se conserva em avéstico aēta"recompensa", no genitivo osco AETEIS "parte" de *ai-ti-, etc.

Como se constata, nestes casos, o adjectivo em -yo- deriva de um substantivo e aparece isolado, não acompanhando um substantivo. O caso de DENSO é, portanto, algo diferente. Tudo aponta para que estejamos perante um adjectivo primário e não um derivado adjectival denominativo. Naturalmente, o que primeiro nos ocorre é que pode tratar-se de um adjectivo relacionado com o latim: densus "denso". E assim seria, efectivamente, se, como se chegou a equacionar, fosse um cognome latino ${ }^{21}$. Apontou J. d'Encarnação naquele sentido, indicando a possibilidade de se estabelecer a comparação com o adjectivo latino, que significando "denso, numeroso, pleno" pode qualificar um elemento vegetal, aquático ou de outra natureza e que, genérica e figuradamente, também se poderia ligar à noção de fecundidade 22 .

Existe, todavia, em nosso entender, uma hipótese mais verosímil. Conhece-se um adjectivo indo-europeu, $* d n s-u$-, que tem o significado de "que conhece ou possui a força mágica, experto, capaz". Encontra-se, por exemplo, no seu grau pleno secundário $* d e m s u$-, no primeiro termo do composto dámsu- de RV 1, 13423. Dado que o expectável da forma original com radical em grau $\emptyset$ seria o índico antigo *dásu-, pode pensar-se que, logo na etapa indo-europeia ou, com mais probabilidade, nas famílias históricas, se produziu a homogeneização do radical a favor do grau pleno próprio do comparativo e do superlativo, que se documenta em índico antigo como dam sistha-. É possível que continue na sua forma regular no hetita dassu- "forte". Além do mais, a ideia de que o indo-europeu - $n$ - deu como resultado - en- em lusitano parece actualmente insustentável, de modo que da forma original $* d n s$ - $u$ - se esperaria regularmente $\dagger$ dansu/o- e não a forma atestada DENSO. Prova disso são os casos evidentes de evolução $-n->$-ane $-m^{-}>-a m-$, como BANDVE "passagem, caminho, entrada", de * $g$ w $m$-tu-, o epíteto PEMANEIECO, de *poi-mn-yaiko- "nutridor, pastor" (?) ou QVANGEIO, de *kwn-k-yo-, derivado da palavra para "cão".

Constata-se, mais uma vez, um facto frequente na onomástica da Hispânia ocidental: o de que, abstraindo-nos da enorme similitude das

21 Vide supra.

22 J. D'ENCARNAÇÃo (1975, p. 174).

23 Cf. EWAIA I, p. 688-689. 
línguas hispânicas ocidentais não-celtas com o grupo indo-europeu ocidental, concretamente com o grupo itálico, também existem notáveis coincidências lexicais entre as áreas laterais extremas do continuиm indo-europeu e que estas apontam para a conservação de formas progressivamente perdidas no espaço central desta vastíssima extensão.

A passagem desta forma à flexão temática parece clara: os adjectivos indo-europeus em - $u$ - tenderam frequentemente a acomodar-se a flexões mais produtivas, o que explica a sua passagem massiva aos temas em - $i$ - em latim, apesar de por vezes se converterem noutras formas temáticas, como sucede como o latim densus vs. índico antigo dasú- "denso". E este fenómeno adaptativo é igualmente bem conhecido nas restantes línguas itálicas ${ }^{24}$. Existe, contudo, uma possibilidade alternativa, que fonética e morfologicamente seria irrepreensível: tratarse de um derivado adjectival primário do substantivo de tema em sibilante *densos "força mágica" (índico antigo dámsas, grego oñyos), isto é *dens-s-o-, do mesmo modo que, exemplificativamente, de *weid-os "aparência, imagem" deriva *weid-s-o- em alto-alemão antigo wis s "sábio", etc. ${ }^{25}$.

Defendeu-se já que a evolução de perda de nasal antes de sibilante com alargamento compensatório da vogal anterior - Vns V- >-V:s V-, que é foneticamente natural e acontece, por exemplo, em latim desde época comparativamente precoce (daí grafias como $-<$ ESIS $>$ por $-<$ ENSIS $>$ ), tinha ocorrido na extremidade ocidental da Hispânia em data anterior à adopção do alfabeto e ao início da cultura escrita. Isto encontra-se claramente espelhado no caso do teónimo em dativo que assume as formas COSSVE, CVSSVE, COSO, em que se parte de um nome de acção *kom-dhH-tu- > *konsu-. A única excepção é um exemplo de CONSO em León, que não reflecte mais do que a interferência do uso gráfico do lusitano-galaico com o latino e que, por conseguinte, se limita a indicar uma pronunciação provável [ko:so:]. Mais a sul, na Lusitânia, encontramos idêntico fenómeno no caso do adjectivo IFADEM da inscrição rupestre do Cabeço das Fráguas, para o qual se reconstruiu um antigo *en-fat-yom "que investe", em que é patente a perda da nasal antes da

24 Cf. R. Gusmani (1965) e, acerca dos novos contributos do dialecto osco para esta questão, o estudo de P. Poccetti integrado em P. Poccetti \& M. Gualtieri (2001, p. 247-248).

25 Cf., em termos genéricos sobre estes tipos formacionais, K. STÜBER (2002, p. 78-79). 
fricativa /f/26. Tomando por base tudo isto, e tendo em conta que COSSVE é uma divindade muito típica da área de implantação ásture ${ }^{27}$, considera-se muito provável que DENSO reflicta uma pronúncia real [de:so:] e que se esteja perante o que se poderia designar como um caso de interferência gráfica. Por outras palavras, qualquer escrevedor latinizado, como não poderia deixar de ser, conhecia a equivalência habitual entre uma pronunciação - V:s V- e uma sequência gráfica que incluía o grupo $-<\mathrm{NS}>-$, e reintroduzia a sequência correcta $-<\mathrm{NS}>-$, inclusive quando escrevia formas de outra língua, com toda a probabilidade a sua própria língua materna.

Mas o mais curioso é que esta interpretação permite estabelecer um paralelismo com o que poderia ser um caso claro de interpretatio romana. Há alguns anos, publicou-se uma epígrafe encontrada em Repeses, imediações de Viseu, na qual se pode ler: ALBVCEL/AINCO / EFFICACI / RVFINVS / RVFI F(ilius) / AELATIVS / V(otum) L(ibens) S(oluit) ${ }^{28}$. Como, então, correctamente indicava o seu editor, EFFICACI é um epíteto inédito e relaciona-se com a força que se atribui à divindade. EFFICACI terá um valor análogo ao de DENSO. Dado que ALBVCELAINCO é o adjectivo que deriva de um topónimo, que por sua vez procede do composto, provavelmente de filiação céltica, *albookelo- "Monte Branco", neste caso chama-se EFFICACI ao genius ou lar que protege a localidade. Deve ser algo de semelhante o que está por trás de DENSO: dá-se a denominação de "dotado de força mágica" ao protector de uma povoação, na realidade, desconhecida para nós, mas não para o dedicante, a qual bem poderia ter sido a que, na época romana, teve existência nos chãos da Quinta de Cilhades.

Mas este não é o único caso em que encontramos a dupla expressão, latina e indígena, de uma mesma ideia. Documenta-se na área de Bracara Augusta, concretamente em Adaúfe ${ }^{29}$, um LARI SEFIO. J. Gorrochategui ${ }^{30}$ interpretou-o correctamente como um Larifamiliaris e

26 Cf. B. M. Prósper (2004).

27 Para além de B. M. Prósper (2004, 225-238 e 440), com rol dos testemunhos conhecidos deste teónimo e interpretação da sua distribuição geográfica, veja-se A. REDENTOR (2006, p. 263-264) a propósito da possibilidade de existência de mais um testemunho, na Astúria meridional.

28 Cf. J. L. I. VAZ (1990).

29 RAP, p. 360, n. ${ }^{\circ} 216$.

30 J. Gorrochategui (1987, p. 85 e n. 38). 
retrotraiu-o a *sebh-yo- "próprio", comparando o gótico sibja "estirpe" (de *sebhyā) e, já na Hispânia, o étnico ocidental Sefes ${ }^{31}$. Esta é a origem do nome dos Sabīnī e dos Samnītes que eram vizinhos dos Romanos e dos Safinús dos textos sudpicenos, que é, provavelmente, na origem a denominação genérica de um amplo grupo itálico, cujo significado ficou associado a povos menores que dele se separaram. A forma SEFIO é, portanto, comparável, no entender deste autor, à dedicatória a um LARI PATRIO documentada em Penafiel (Porto) ${ }^{32}$, a que podemos acrescentar os LARIBVS PATRIIS de uma epígrafe de Mortágua (Viseu) ${ }^{33}$, invocação que é pouco usual no mundo romano.

\section{Nota final}

A inscrição de Cilhades, agora deslocada do seu local de achado para a aldeia do Felgar, é indubitavelmente um altar votivo. É, em nossa opinião, datável do século II ou da primeira metade da centúria seguinte.

O indivíduo que a consagrou desfrutaria da plenitude dos direitos de cidadania; no entanto, não nos é possível conhecer o seu nome, pois foi tomada a opção de o apresentar por meio de siglas. Poder-se-ia, à partida, pensar numa questão de piedade estrita para explicar a preferência pelo anonimato da dedicatória, mas se olharmos para o contexto arqueológico do achado e pensarmos no ambiente social regional, teremos que encontrar outra explicação para o caso. Num quadro de características rurais, como aquele em que o habitat romano ${ }^{34}$ a que a ara aparece associada se integrava, não seria, então, difícil decifrar o nome abreviado do cidadão que a dedicou. Quiçá se reduza a uma questão de economia a opção tomada, pois estamos em crer que o resultado em nada teria frustrado os intentos socioreligiosos de M. R. S. C. f.

31 Avieno, Ora maritima 195, na realidade transmitido como Saefes.

32 RAP, p. 421, n. ${ }^{\circ} 383$.

$33 R A P$, p. 420, n. $^{\circ} 380$.

34 É classificado como aldeia por F. S. Lemos (1993, p. 355, n. ${ }^{\circ} 681$ ), o qual, com base na proximidade do sítio à área de exploração mineira de Vale de Ferreiros e do Cabeço da Mua, levanta a hipótese de ter produzido excedentes para os núcleos de povoamento ligados à actividade metalúrgica, em função da existência de condições propícias ao desenvolvimento da policultura. 
Nela invoca-se DENSO, ente divino cuja qualificação não conhece até hoje qualquer outro registo. A sua denominação adjectival, tipologicamente minoritária no âmbito do panorama religioso lusitano-galaico, recorda a eficácia operativa da sua dimensão tutelar. Vemo-lo como nume protector de um aglomerado populacional, apelidado em função de uma das suas principais qualidades: ser "dotado de força mágica".

\section{BIBLIOGRAFIA}

Abascal Palazón, J. M. (1994), Los nombres personales en las inscripciones latinas de Hispania, Murcia: Universidad, Secretariado de Publicaciones, [Madrid]: Universidad Complutense (Arqueología; 1. Anejos de Antigüedad y cristianismo; 2).

BRANDÃo, D. de P. (1961), «Denso - uma nova divindade bárbara do panteão lusitano», Lucerna, 2:1, p. 26-28.

Carqueja, M. da C.; Rodrigues, A. V. (2006), Felgar, s. 1.: autores.

CIL II = HÜBNER, E. (1869), Inscriptiones Hispaniae Latinae, Berolini: Gergium Reimerum (Corpus Inscriptionum Latinarum; 2).

HÜBNER, E. (1892), Inscriptiones Hispaniae Latinae: Supplementum, Berolini: Gergium Reimerum (Corpus Inscriptionum Latinarum; 2).

CRUZ, C. (2000), A paisagem e o povoamento na longa duração: o Nordeste Transmontano - Terra Quente, 2, Braga: [s. n.] (Tese de mestrado em Arqueologia da Paisagem, Universidade do Minho).

De Simone, C. (1992), «Sudpiceno Safìno-/lat. Sabīno-: Il nome dei Sabīn̄̄», Annali dell'Istituto Universitario Orientale di Napoli, 14, p. 223-239.

DIP = uide ENCARNAÇão, J. D' (1975).

EnCARNAÇão, J. D' (1975), Divindades indígenas sob o domínio romano em Portugal: subsídios para o seu estudo, Lisboa: Imprensa Nacional-Casa da Moeda.

EWAIA = uide MAYRHOFER, M. (1992).

GARCIA, J. M. (1991), Religiões antigas de Portugal: aditamentos e observações às Religiões da Lusitânia de J. Leite de Vasconcelos: fontes epigráficas, [Lisboa]: Imprensa Nacional-Casa da Moeda (Temas portugueses).

GORROCHATEGUI, J. (1987), «En torno a la clasificación del lusitano», in GorRochategUI, J., Melena, J. L., Santos, J., eds., Studia Palaeohispanica, Actas del IV Coloquio sobre Lenguas y Culturas Paleohispánicas, Vitoria, p. 77-92.

GRUPo MérIDA (2003), Atlas antroponímico de la Lusitania romana, Mérida / Bordéus: Fundación de Estudios Romanos / Ausonius Éditions.

Gusmani, R. (1965), «Note marginali sulla declinazione osco-umbra», Rendiconti del Reale Istituto Lombardo di Scienze e Lettere (RIL): Classe di Lettere, 99, p. 380-388 .

IEW = uide POKORNY, J. (1959).

KaJAnto, I. (1965), The Latin Cognomina, Helsinki: Helsingfors (Commentationes Humanarum Litterarum. Societas Scientiarum Fennica; 36. 2). 
Lemos, F. S. (1993), O povoamento romano de Trás-os-Montes Oriental, IIa, Braga: [s. n.] (Tese de doutoramento em Pré-História e História da Antiguidade, Universidade do Minho).

LÖRINCZ, B. (1999), Onomasticon Prouinciarum Europae Latinarum (OPEL), vol. 2: Cabalicius - Ixus, Viena: Forschungsges.Wiener Stadtarchäologie.

LÖRINCZ, B. (2002), Onomasticon Prouinciarum Europae Latinarum (OPEL), vol. 4: Quadratia - Zures, Viena: Forschungsges.Wiener Stadtarchäologie.

MAYRHOFER, M. (1992), Etymologisches Wörterbuch des Altindoarischen, I-II, Heidelberg: Winter Verlag.

Navarro Caballero, M. (1998), «Las estelas en brecha de Santo Adrião: observaciones tipológico-cronológicas», Boletín del Seminario de Estudios de Arte y Arqueología, 64, p. 175-206.

Poccetti, P., Gualtieri, M. (2001), La tabula bronzea di Roccagloriosa, Nápoles: Centre Jean Bérard.

POKORny, J. (1959), Indogermanisches Etymologisches Wörterbuch, Berna: Francke.

PRÓSPER, B. M. (2002), Lenguas y religiones prerromanas del occidente de la Península Ibérica, Salamanca: Ediciones Universidad de Salamanca (Acta salmanticensia. Estudios filológicos; 295).

Prósper, B. M. (2004), «Varia Palaeohispanica Occidentalia: I. Lusitano TAVrom

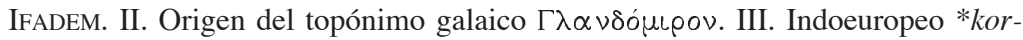
(y)o- "ejército" en Hispania. IV. Un superlativo hispano-celta *kintúsamos y una cuestión de acento», Palaeohispanica, 4, p. 169-194.

$R A P=$ uide GARCIA, J. M. (1991).

REDENTOR, A. (2006), «Manifestações religiosas e onomástica na ciuitas Zoelarum», Conimbriga, 45, p. 253-273.

STÜBER, K. (2002), Die primären s-Stämme des Indogermanischen, Wiesbaden: Dr. Ludwig Reichert Verlag.

Tranoy, A. (1981), La Galice romaine: recherches sur le Nord-Ouest de la Péninsule Ibérique dans l'Antiquité, Paris: De Boccard (Publications du Centre Pierre Paris; 7. Collection de la Maison des Pays ibériques; 7).

VAZ, J. L. I. (1990), «Ara votiva a Albucelaincus», Ficheiro Epigráfico, 35, n. ${ }^{\circ} 157$. 
Est. I
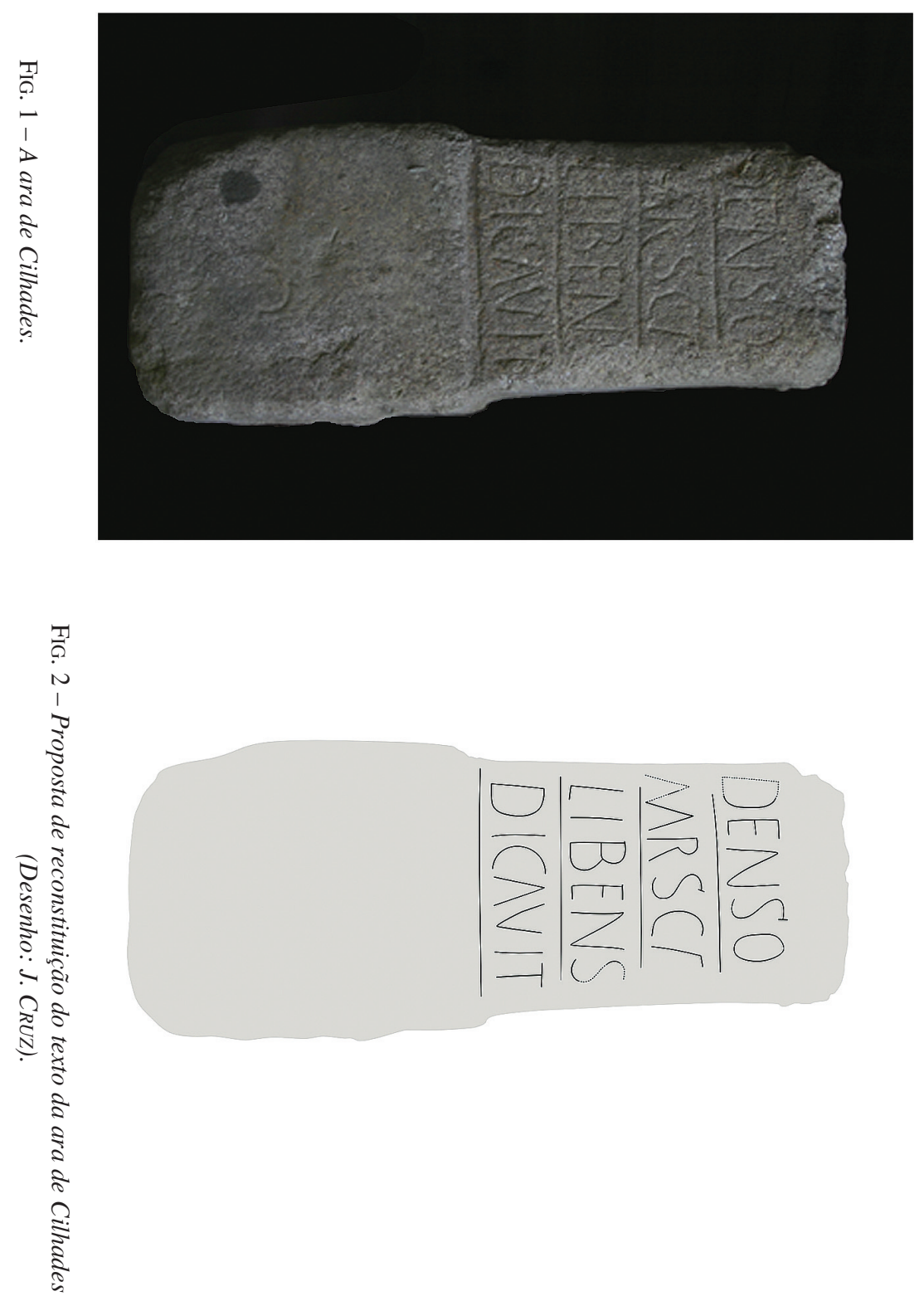